\title{
Professional development and the recently qualified information and library studies professional: factors affecting success in attainment of the Library Association's
} Associate status

\section{Fiona Campbell, Rita Marcella and Graeme Baxter}

\author{
The School of Information and Media \\ The Robert Gordon University
}

\begin{abstract}
Aberdeen
Abstract: This paper describes a project funded by the UK Library Association (LA) which sought to investigate factors impacting upon length of time taken to achieve Associateship of the Library Association and to gather attitudinal data as to the benefits of Associateship, barriers to successful completion and continuing professional development (CPD). Data was gathered via a postal questionnaire (38.3\% response rate) and telephone interviews with not yet complete and withdrawn candidates. The respondent group reflected a representative sample of the research target, coming from a range of employment sectors. Results suggested that significant factors included: conflicting pressures, lack of time, loss of interest and poor supervision. Those candidates still to submit or who had withdrawn tended to have received less support from employers. Associateship was seen as advantageous largely in that it conferred chartered status and professional recognition: fewer respondents felt that it had, or was likely to, lead to an enhanced career, a salary increase or prestige. The majority of respondents were interested in their personal continuing professional development (93.5\%), reading professional literature as part of their CPD (85\%), while between a half and two thirds attended external seminars/courses, networked with colleagues and engaged in internal training activities. A slight majority (54.2\%) felt that CPD should not be compulsory: some suggested a system of reward rather than a compulsory approach should be preferred.
\end{abstract}

\section{Introduction and background to the project}

The rationale for this study arose from the fact that staff at the UK Library Association (LA) Professional Qualifications Department had noted that, while a proportion of candidates complete the requirements for Associateship quickly after registering, a substantial number 
follow a quite different pattern: some take several years to complete; some have still to submit several years after registration; and a number drop out of the registration process completely. There are currently 3,200 information professionals registered as candidates for Associateship of the Library Association (ALA) and it is estimated that between two-thirds and half of those have been registered for longer than necessary.

It was felt that it was important to develop a better understanding of the reasons underlying completion and non-completion, in order to ensure that new professionals were offered the best possible support in attaining recognised professional status and to explore respondents' attitudes to issues of professionalism, professional status and the relationship between LA Associateship and the individual's Continuing Professional Development (CPD) and career progression. The last aspect of the study would also enable evaluation of the usefulness of the Library Association's CPD Framework.

At a time when the merger of the Library Association and the Institute of Information Scientists seems set to go ahead, the project results are timely in providing evidence for the consideration of the future mechanisms to be put in place in order to ensure that those attaining professional status can demonstrate professionalism and maturity and in debate as to the extent to which it may be desirable for ongoing and compulsory CPD to be made a requirement for those retaining professional status, as is currently being implemented by other professions.

There are currently two routes available to Associateship candidates; either may be followed by individuals who have gained an LA accredited degree or postgraduate qualification.

Route $\boldsymbol{A}$ candidates must complete at least one year of supervised professional training approved by the LA. This training will be supervised by a Chartered Member of the LA who has been on the Register for at least five years.

Route B candidates can apply for Associateship after completing two years' work experience without direct supervision and without following an LA-approved training programme. This route is also open to candidates who do not have a formal qualification in library and information studies.

The subsequent application for both types of candidate can take various forms. The candidate may have to submit a Professional Development Report (PDR), which is a personal 
evaluative account of his/her professional development from the point of obtaining an LIS qualification to the time of making the Associateship application

\section{Literature review}

There have been a number of general overviews of the benefits of CPD and key issues in its planning and provision in the library and information profession [for example, 1,2,3,4]. Others have focused on particular sectors: for example, Elkin [5] highlighted the need for a strategic approach to CPD in both the academic and public library sectors, while Doney [6] investigated staff attitudes to CPD in the business and academic sectors. The role of professional associations in supporting and raising awareness in professional development was outlined by Hyams [7]; while Elkin [8] considered how UK library schools might contribute to CPD.

Abell [9] pointed to the growing opportunities for LIS professionals, particularly with the rapid development of Information and Communication Technologies (ICT), and the need for professionals to supplement their traditional skills with new attributes (e.g. leadership and management skills, strong inter-personal and communication skills, negotiation and motivation skills, and systems and ICT skills) if they are to take advantage of these new opportunities.

The relationship between CPD and career success in three professions (information, accountancy and human resources management) was explored by Farmer and Campbell [10]. Although information professionals regarded CPD as a factor influencing career success, it was viewed as less influential than networking, personality, ability, experience and hard work. In earlier research, the same authors found evidence that some information professionals were apathetic about participating in CPD, sceptical about its benefits, suspicious about 'getting involved' or confused about the activities that might constitute CPD [11].

A number of authors $[11,12,13]$ have investigated the role that mentoring can play in professional development. Levy [14] described the development of an Internet-based CPD course funded as part of the UK Higher Education Funding Councils' Electronic Libraries (eLib) programme; while Horseman [15] discussed the effectiveness of CD-ROM as a professional development tool. 
Swaffield [16] examined how other professions (including healthcare, engineering and town planning) approached CPD, the degree to which it was seen as compulsory within these sectors, and how they were dealing with the common problem of evaluating professional development.

The Library Association has been prominent in encouraging LIS professionals to take responsibility for their own career development and, in 1992, produced its Framework for Continuing Professional Development, a pack of self-help documents distributed free to all LA members [17]. Several authors have discussed the principles, benefits and implications of this Framework [for example, 18,19,20], while both Redfern [21] and Nankivell [22] have investigated the extent of use of the Framework. The last author found that around a quarter of respondents were using the Framework but warned that, because respondents were all members of the LA's Personnel Training and Education Group, the findings could not be considered typical of the profession as a whole.

A substantial proportion of the literature has focused on the professional qualifications awarded by the Library Association. The LA's revised regulations for Associateship candidates were described by Wood [23], and Huckle [24] explained why Associateship is important to individual members and to employers. Atton [25] provided suggestions as to how candidates should write their Professional Development Report, while Kempshall and Casey [26] described the role and problems faced by candidates' supervisors. Burton and Huckle [27] and Turriff [28] discussed the LA's proposal to establish a formal network of mentors to support Route B candidates and appealed for volunteer mentors.

On an international level, while the American Library Association (ALA), the largest professional body in North America, does not operate a certification-based membership scheme, the Medical Library Association (i.e. of the United States) operates a peer-reviewed professional development and career recognition programme - the Academy of Health Information Professionals. Open to members and non-members with an ALA-accredited library science qualification, this scheme requires applicants to complete a 'portfolio of professional progress' which documents a candidate's progress through the 'credentialing process'. The membership level of the Academy is based upon CPD points earned, and membership must be renewed at least every five years. Members with less than five years of professional experience in health information sciences - 'provisional members' - are assigned a mentor and must obtain eight points of CPD each year [29]. 
The Library and Information Association of New Zealand Aotearoa (LIANZA) operates an Associateship scheme for individuals who have completed at least five years of satisfactory library service since gaining a library qualification, of which at least three years have been spent in a New Zealand Library. Applicants have to produce: a written application; a written personal record of at least 1,000 words; at least three written referees' reports; and evidence of written work, such as articles, reports, annotated bibliographies and service guides. Applicants also have to be interviewed by at least three members of the LIANZA Credentials Committee [30].

Many library associations throughout the world have affirmed their commitment to CPD. For example, the main aim of the American Library Association Office for Human Resource Development and Recruitment is 'to facilitate the development of librarianship as a profession'. It operates a Continuing Library Education Network and Exchange Round Table which provides a forum for the exchange of ideas and concerns among library and information personnel responsible for continuing library education, training and staff development [31]. The strategic plan of the Special Libraries Association (i.e. of the United States) notes that one if its main values is 'a recognized need for continuous learning and professional development to maintain leading edge skills' [32]. It is currently developing a mentoring scheme, and recently distributed a mentorship handbook to its various chapters and divisions. The Canadian Library Association, meanwhile, lists as one of its achievements its professional development programme, which includes the annual conference, local seminars and teleconferences [33].

In Australia, the Board of Education of the Australian Library and Information Association (ALIA) is responsible for the professional development of its members. It has developed a career planning kit, which includes the Association's CPD policy statement, guidelines for accessing professional development opportunities, and a planning workbook to assist members in the process of planning and recording career development. In 2000, ALIA is to introduce a new subcategory of membership which will recognise its members' CPD by awarding the post-nominal letters ' $\mathrm{CP}$ ' (certified practitioner). Participants will have to undertake a minimum of 20 hours of CPD annually, with a total of 80 hours to be gained over each three-year reporting period [34].

IFLA, the International Federation of Library Associations and Institutions, established a Round Table on Continuing Professional Education (CPERT) in 1986. Its goals for the period 1998-2001 include: 'to encourage and develop international continuing professional education programmes for library and information personnel'; and 'to stimulate research in 
continuing education for library and information professionals' [35]. The Proceedings of CPERT's most recent international conference contain papers on CPD developments and issues in countries as diverse as Brazil, China, Estonia, Hungary, Israel and Nigeria [36].

\section{Aims, objectives and methodology}

This study aimed to examine the factors that have an impact upon the length of time taken to achieve Associateship of the UK Library Association and to gather attitudinal data from candidates about the benefits of Associateship and any barriers to successful completion of applications.

The objectives of the study were to:

1. Identify the factors that underlie different patterns of achievement in relation to gaining Associateship

2. Investigate the support necessary for candidates to achieve Associateship and to help them identify training needs and construct career plans in the early stages of their professional life

3. Make recommendations as to the most effective patterns of support and progress in order to maximise success in achieving Associateship

4. Audit the extent of use of the LA CPD Framework and other career planning methods

5. Gather attitudinal data as to new professionals' perceptions of professional status and its relationship to their personal CPD

6. Investigate new professionals' attitudes to CPD and their perception of its significance

The major element of the research was a questionnaire-based survey of four distinct groups:

- those individuals who achieved Associateship during the period March 1998 to March 1999 ;

- candidates who had registered for Associateship in 1995 but who had not yet submitted their applications;

- individuals who had defaulted or resigned as Associateship candidates during 1999; and

- current Associateship supervisors 
A separate, tailored questionnaire was produced for each group. Prior to their dissemination, the questionnaires were piloted. Names and addresses of individuals belonging to each group, arranged in alphabetical order, were supplied by the Library Association. Using systematic sampling (i.e. every $n$th name on the list, with $n$ dependent on the total number of names on the list, and the first name on the list being used as the starting point) 100 people in each group were selected and sent a questionnaire.

Overall response rate was a valid 38.3\% (153 responses). The response from recently elected Associates (58\%) and supervisors (51\%) was good but, perhaps unsurprisingly, that of the individuals who had not yet completed (30\%) and, in particular, those who had dropped out of the process $(14 \%)$ was less positive. Unfortunately, time restraints prevented any attempts to follow up non-respondents.

In common with all sample surveys, the results presented here are subject to margins of error. With this in mind, Table 1 provides the margins of error, for $95 \%$ confidence levels, based on the full sample size of 153. The table indicates the margin of error (plus or minus) associated with the sample size of 153 and with various percentage values. For example, a percentage value of $60 \%$ (or, of course, $40 \%$ ) has a margin of error of $\pm 7.8 \%$. This indicates that the true value of the result (at the 95\% confidence interval) lies within the range 52.2\% and $67.8 \%$.

\begin{tabular}{|c|c|c|}
\hline \multicolumn{3}{|c|}{ Table 1: Margins of error based on full sample } \\
\hline Sample Size & $\begin{array}{c}\text { Percentage } \\
\text { Value }\end{array}$ & $\begin{array}{c}\text { Margin of } \\
\text { Error }\end{array}$ \\
\hline 153 & $50 / 50$ & $\pm 7.9 \%$ \\
\hline$"$ & $60 / 40$ & $\pm 7.8 \%$ \\
\hline$"$ & $70 / 30$ & $\pm 7.3 \%$ \\
\hline$"$ & $80 / 20$ & $\pm 6.4 \%$ \\
\hline$"$ & $90 / 10$ & $\pm 4.8 \%$ \\
\hline
\end{tabular}

The data from the completed questionnaires were analysed using the statistical package SPSS for Windows, and significant statistical relationships between variables (at the 95\% confidence level) were identified using the chi-square test. It should be emphasised, though, that because of the low numbers of respondents in the group who had not yet submitted, and in particular the group who had defaulted/resigned, some of the inter-group comparative figures should be treated with caution. Equally, the overall results may tend to demonstrate a bias in favour of the views of the successful candidates and supervisors. 
On their respective questionnaires, those individuals who had not yet completed the Chartership process or who had withdrawn from the process were asked if they would be willing to participate in follow-up telephone interviews, designed to: elicit more detailed information on the factors affecting non-completion of the Chartership process; examine the respondents' progress and patterns of work on the process to date; and obtain suggestions on how barriers to completion might be overcome.

Of the 30 responding individuals who had yet to complete their Chartership, 20 indicated that they would be willing to participate in a telephone interview. Thirteen were interviewed, while the remainder proved unobtainable. Of the 14 respondents who had withdrawn from the Chartership process, nine were willing to be interviewed and six of these were actually interviewed. Nineteen interviews were, therefore, carried out using a formal proforma. Results were analysed to identify important themes and issues emerging. The results of the interviews, by focusing upon non-completed and withdrawn candidates, help to redress any bias in the survey data.

\section{Personal details of respondents}

The first section of the questionnaire sought to obtain some personal details from the respondents. The gender breakdown is close to that of the Library Association membership as a whole (Female $75.8 \%$; Male $24.2 \%^{1}$ ), although there was a noticeably higher proportion of males amongst the supervisors' group (39.2\%). It should be emphasised, however, that no conscious efforts were made to match the personal characteristics of the sample with that of the LA membership via quota sampling.

The survey sample had a greater proportion of individuals aged under $30(27.5 \%)$ than in the LA membership as a whole $(12.9 \%)$; while the proportion of the sample aged 55 or over (4.6\%) was less than that in the entire membership (13.7\%). These data are to be expected given that the survey target mainly consisted of recently registered professionals. The supervisors group tended naturally to be older. Interestingly, a substantial proportion (10 of 14) of the respondents who had withdrawn from the Chartership process were aged between 30 and 44. 
The majority of survey respondents worked in academic (34.6\%) or public (30.1\%) libraries (see Table 2). In fact, the proportions were considerably higher than that for the LA membership as a whole (17.6\% in academic libraries; $24.9 \%$ in public libraries), although in the case of the public libraries this has been influenced by the high proportion (39.2\%) of responding supervisors who work in that sector. The proportion of the sample working in health/medical libraries (7.2\%) was also higher than that in the entire LA membership (2.9\%).

\begin{tabular}{|c|c|c|c|c|c|c|c|c|c|c|}
\hline \multirow[b]{2}{*}{ Sector } & \multicolumn{2}{|c|}{$\begin{array}{l}\text { Recently } \\
\text { elected }\end{array}$} & \multicolumn{2}{|c|}{$\begin{array}{c}\text { Not } \\
\text { submitted }\end{array}$} & \multicolumn{2}{|c|}{$\begin{array}{c}\text { Defaulted/ } \\
\text { resigned }\end{array}$} & \multicolumn{2}{|c|}{ Supervisors } & \multicolumn{2}{|c|}{ Total } \\
\hline & No. & $\%$ & No. & $\%$ & No. & $\%$ & No. & $\%$ & No. & $\%$ \\
\hline Academic & 23 & 39.7 & 7 & 23.3 & 5 & 35.7 & 18 & 35.3 & 53 & 34.6 \\
\hline Public & 15 & 25.9 & 8 & 26.7 & 3 & 21.4 & 20 & 39.2 & 46 & 30.1 \\
\hline $\begin{array}{l}\text { Industry/ } \\
\text { commercial }\end{array}$ & 5 & 8.6 & 4 & 13.3 & 2 & 14.3 & 1 & 2.0 & 12 & 7.8 \\
\hline Health & 6 & 10.3 & 1 & 3.3 & - & - & 4 & 7.8 & 11 & 7.2 \\
\hline School & 4 & 6.9 & 3 & 10.0 & 1 & 7.1 & 3 & 5.9 & 11 & 7.2 \\
\hline Government & 2 & 3.4 & 1 & 3.3 & - & - & - & - & 3 & 2.0 \\
\hline National & - & - & - & - & - & - & 1 & 2.0 & 1 & 0.7 \\
\hline Other* & 2 & 3.4 & 2 & 6.7 & - & - & 4 & 7.8 & 8 & 5.2 \\
\hline $\begin{array}{l}\text { Employed } \\
\text { outside LIS }\end{array}$ & 1 & 1.7 & 1 & 3.3 & 1 & 7.1 & - & - & 3 & 2.0 \\
\hline $\begin{array}{l}\text { Not in paid } \\
\text { employment }\end{array}$ & - & - & 2 & 6.7 & 2 & 14.3 & - & - & 4 & 2.6 \\
\hline No response & - & - & 1 & 3.3 & - & - & - & - & 1 & 0.7 \\
\hline Totals & 58 & 100 & 30 & 100 & 14 & 100 & 51 & 100 & 153 & 100 \\
\hline
\end{tabular}

* The 'other' sectors were: charitable/voluntary 4; art gallery 1; legal 1; professional body 1; research 1.

Almost $45 \%$ of the sample had their first or only degree in library and information studies, while just under half $(49.7 \%)$ had a postgraduate qualification in LIS. Just under $6 \%$ indicated that they had no formal LIS qualification.

Respondents were asked how recently they had obtained their LIS qualification. The majority of the recently elected (74.2\%) and the currently registered (66.6\%) respondents had qualified in LIS within the last six years, but more than half (eight of 14) of the recently defaulted/resigned candidates had qualified seven or more years ago. The vast majority of the supervisors $(98.0 \%)$ had qualified nine or more years ago. It should be noted that, in the response to the previous question, nine individuals indicated that they had no LIS qualification; here, however, the suggestion was that only one of the respondents was not qualified in LIS.

\footnotetext{
${ }^{1}$ Details of the entire LA membership, at $30^{\text {th }}$ June 1999 , were provided by the Library Association's Professional Qualifications Department.
} 


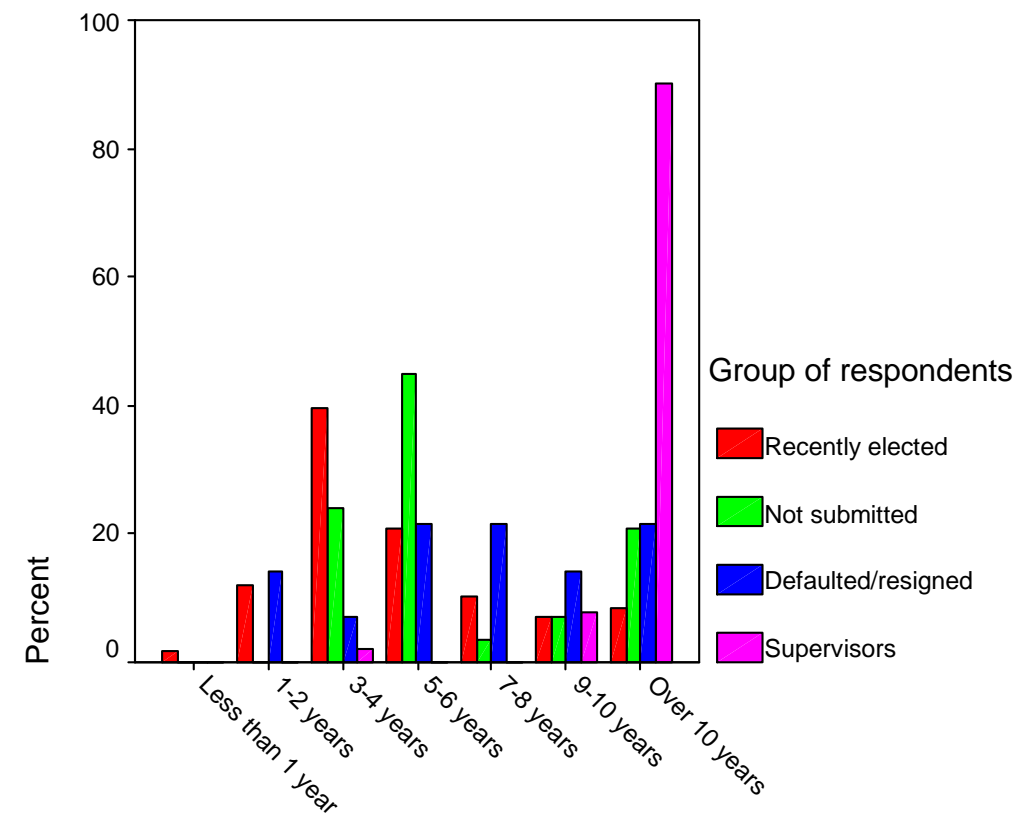

Figure 1: How recently respondents qualified in LIS

\section{Registration process and Route to Associateship taken}

With the exception of those in the supervisors' group, respondents were asked how recently after qualifying in LIS they had registered for Associateship. The vast majority (73.6\%) of respondents had registered within two years of obtaining their qualification, while almost $20 \%$ did so between three and eight years after qualifying. Seven respondents had waited over 10 years before deciding to register.

The majority of respondents were Route A candidates (64, 62.7\%), while 32 (31.4\%) had chosen Route B and six (5.9\%) did not specify their route. Most Route A candidates had selected that particular route because it was offered and supported by their employer, while a smaller number indicated that it was because it was the 'quickest', 'easiest' or 'most appropriate' route. Route B was generally selected because the respondents' employers could not offer suitable supervisors and/or training programmes.

A small number of respondents had changed route during the course of the Chartership process. Most of those who had moved from Route A to B explained that they had changed jobs and that their new employer did not support a Route A programme, while one respondent indicated that increasing work pressures meant that the Route A training programme could not be sustained. The two respondents who had moved from Route B to A were employed by 
organisations who did not support a Route A programme and were initially unaware of that option; both had subsequently sought out external supervisors in order to transfer to Route A.

Table 3 indicates success in completion for the two specified routes.

\section{Table 3: Success rate for each Route}

\begin{tabular}{|l|c|c|c|c|}
\hline & \multicolumn{2}{|c|}{ Route A } & \multicolumn{2}{c|}{ Route B } \\
\hline Recently elected & 38 & $59.4 \%$ & 18 & $56.3 \%$ \\
\hline Not submitted & 16 & $25.0 \%$ & 12 & $37.5 \%$ \\
\hline Defaulted/resigned & 10 & $15.6 \%$ & 2 & $6.2 \%$ \\
\hline Totals & $\mathbf{6 4}$ & $\mathbf{1 0 0 \%}$ & $\mathbf{3 2}$ & $\mathbf{1 0 0 \%}$ \\
\hline
\end{tabular}

Results would, therefore, suggest that the Route chosen has little impact upon successful completion, but that a slightly greater proportion of Route B candidates have not submitted after a number of years, while a greater proportion of Route A candidates have defaulted or resigned from the process.

The group of 58 respondents who had achieved Associateship during 1998-99 were asked how long it had taken them to complete the requirements (see Figure 2). The majority (62.1\%) had completed the process within two years, while a further $29.3 \%$ had taken between two and five years. For five respondents $(8.6 \%)$ the process had taken over five years to complete; one of these had taken 12 years. 


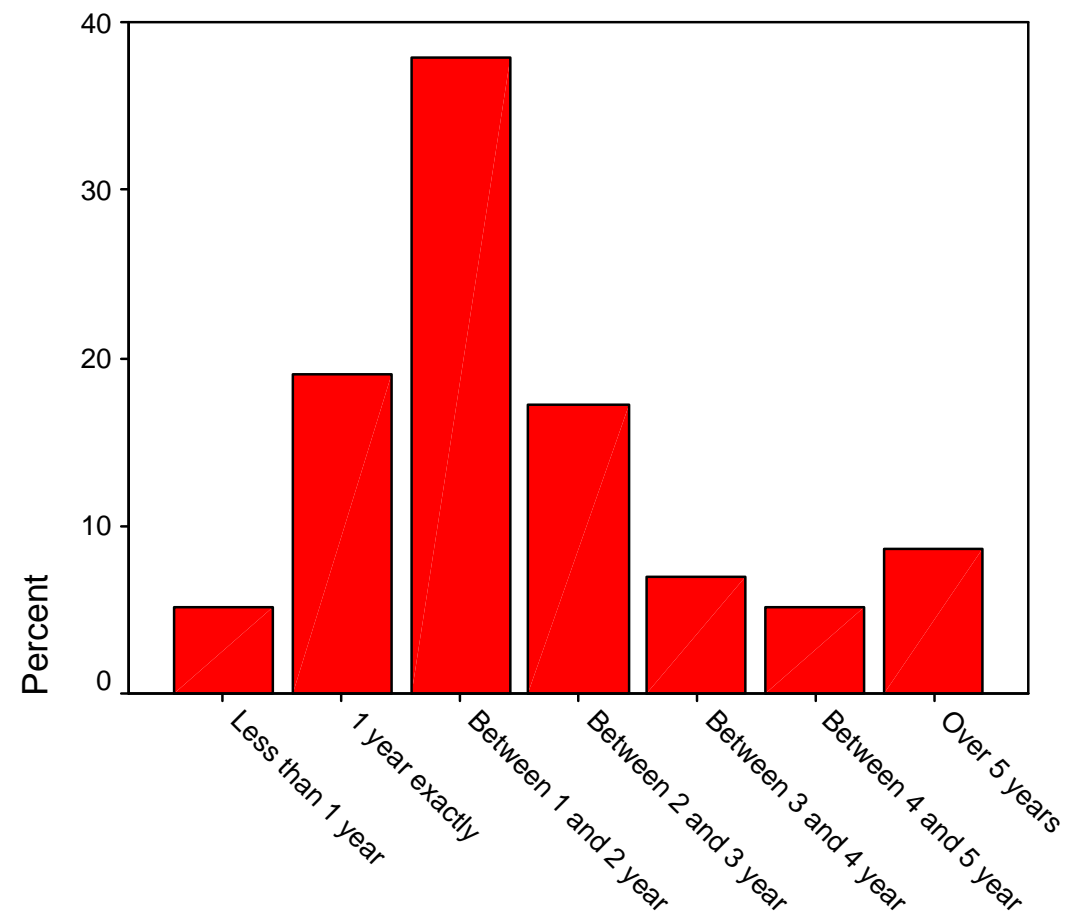

Figure 2: How long respondents took to complete requirements for Associateship

In contrast, the 30 respondents who had not yet submitted their applications were asked if they felt they were making good progress towards completion. Only eight (26.7\%) felt that their progress to date was satisfactory, while $22(73.3 \%)$ felt that no great progress had been made.

In the follow-up telephone interviews, the 13 respondents who had yet to complete their application were asked to provide more details about their progress. One respondent had since submitted their application, but four had yet to embark on the writing-up process. One had completed a rough draft of their PDR; two had written around 50\% of the report; three had completed it in note form only; while another had just commenced writing up. The remaining respondent explained that in her organisation (a public library authority) Associateship candidates have to write a report for the senior management team which has to be approved by them before a PDR can be submitted to the LA; this report has been continuously rejected and resubmitted throughout the last two years. Most of the respondents who had written at least part of their PDR acknowledged that its contents would now be outof-date and would require revision. 
When asked if they could forecast a likely submission date, two respondents hoped to complete by the end of 1999, while another suggested March 2000 as a possible target. Four respondents could not offer a likely date, as other work and domestic pressures currently had priority. One candidate was studying towards an MA, therefore the Chartership had been put on the back burner for at least another $1 \frac{1 / 2}{2}$ years. The remaining four were considering dropping out of the process completely, due to a lack of incentive and employer support.

The 14 defaulted/resigned candidates in the survey sample were asked for how long they had been registered before deciding not to continue with the Chartership process. While five respondents had decided to withdraw within two years of registration, an identical number had been registered for five years or more before deciding to discontinue the process.

\section{Factors affecting completion of Associateship process}

Those respondents who had not yet submitted their applications or who had withdrawn completely from the process were asked to indicate, from a list of nine factors, which had had an impact upon the completion of their applications. Table 4 illustrates the response. More than half of the respondents cited conflicting pressures, a lack of time or a loss of interest in achieving Associateship, while over $40 \%$ blamed poor supervision.

\begin{tabular}{|l|c|c|c|c|c|c|}
\hline Table 4: Factors affecting completion of the Chartership process & \multicolumn{2}{c|}{$\begin{array}{c}\text { Total } \\
\text { Defaulted/ } \\
\text { resigned } \\
\text { (30 respondents) }\end{array}$} & \multicolumn{2}{|c|}{$\begin{array}{c}\text { (14 respondents) } \\
\text { (4espondents) }\end{array}$} \\
\hline Factor & No. & $\mathbf{\%}$ & No. & No. & \% \\
\hline Conflicting pressures & 20 & 66.7 & 8 & 57.1 & $\mathbf{2 8}$ & $\mathbf{6 3 . 6}$ \\
\hline Lack of time & 16 & 53.3 & 8 & 57.1 & $\mathbf{2 4}$ & $\mathbf{5 4 . 5}$ \\
\hline Loss of interest & 16 & 53.3 & 8 & 57.1 & $\mathbf{2 4}$ & $\mathbf{5 4 . 5}$ \\
\hline Poor supervision & 13 & 43.3 & 5 & 35.7 & $\mathbf{1 8}$ & $\mathbf{4 0 . 9}$ \\
\hline Lack of support & 10 & 33.3 & 6 & 42.9 & $\mathbf{1 6}$ & $\mathbf{3 6 . 4}$ \\
\hline Change of career direction & 8 & 26.7 & 5 & 35.7 & $\mathbf{1 3}$ & $\mathbf{2 9 . 5}$ \\
\hline Unclear guidelines & 5 & 16.7 & 5 & 35.7 & $\mathbf{1 0}$ & $\mathbf{2 2 . 7}$ \\
\hline Insufficient information & 7 & 23.3 & 1 & 7.1 & $\mathbf{8}$ & $\mathbf{1 8 . 2}$ \\
\hline Career break & 3 & 10.0 & 2 & 14.3 & $\mathbf{5}$ & $\mathbf{1 1 . 4}$ \\
\hline
\end{tabular}

Additional factors cited included: changes to the way in which Associateship operates; temporary contracts; illness; change of jobs; local government reorganisation; personal problems; the costs involved in chartering; and a lack of incentive due to public libraries appointing unchartered librarians to professional posts. 
The 14 respondents who had defaulted or resigned from the Chartership process were asked to provide details of the main reasons why they had decided not to continue. Many of the responses echoed those provided above, namely: a lack of time due to other work and personal commitments; a lack of support from employers and supervisors; the restrictive costs of LA subscriptions and PDR submission charges; and a change of career direction. Two of the respondents cited what might be described as 'study fatigue'. Six respondents felt that there was little incentive to complete the process in terms of financial reward or career progression.

Issues affecting the completion of the process were also explored in a question to the supervisors' group. They were asked to indicate which factors they believed to be influential in encouraging or discouraging candidates from completion. Encouraging factors were believed to be: improved career prospects and/or financial rewards following the attainment of Associateship; the status attached to the qualification; peer pressure (i.e. in organisations where 'everybody else has it'); and good supervisors and training programmes. Discouraging factors, many of which have already been outlined above, were: a lack of time, due to conflicting work and domestic commitments; a lack of tangible rewards, such as promotion or pay increases; the costs involved in submitting an application and in maintaining LA membership; the unlimited timescale for completion, which can lead to complacency and procrastination; having to write the PDR, particularly for those who have just finished a period of study; and poor supervision and training provision.

\section{Effects of unlimited timescale on completion of Associateship process}

From the time of registering for the Associateship process, candidates are given an unlimited period to submit their final application. In this respect the UK scheme differs from the two other 'certification-based' programmes outlined above. In the LIANZA Associateship scheme, for example, there is no registration period as such: applications are considered annually, and the entire application and interview process is completed within the space of a few weeks. Meanwhile, membership of the Medical Library Association's Academy of Health Information Professionals is renewable every five years; therefore, applicants must complete a certain level of CPD activity within each five-year period.

In the survey, all four groups were asked for their feelings concerning the unlimited time given to candidates for completion of the Chartership process. Overall, opinions were divided 
evenly, with approximately one-third of the sample believing that this was beneficial, a further third believing it was not beneficial, and the final third indicating that they were undecided. There were some significant differences between the groups, however, with greater proportions of those who had not yet submitted their applications (40\%) and, in particular, the supervisors (49\%) believing that the lack of a deadline was not beneficial.

Of the 49 respondents who felt an unlimited timescale was beneficial, $36(73.4 \%)$ indicated that it allowed candidates to deal both with the Chartership and with any other work or personal commitments. Several respondents specified their own personal commitments, such as looking after a young family, moving home, caring for sick or elderly relatives and studying part-time for a higher degree. Four $(8.2 \%)$ of the 49 respondents felt that the unlimited timescale gave them the opportunity to gain enough suitable experience to write about in the PDR.

Of the 52 respondents who believed that the lack of a deadline was not beneficial, the vast majority $(48 ; 92.3 \%)$ felt that it encouraged procrastination. Two respondents believed that it allowed too much experience to accumulate, which would then be difficult to handle within the word constraints of the PDR. The majority (77.8\%) of those who were undecided offered mixed opinions: they agreed that the lack of a deadline might affect candidates' motivation, but felt that a degree of flexibility was essential to allow for the applicants' personal circumstances.

In an additional question, the supervisors' group was asked if the unlimited timescale increased candidates' motivation. Of the 51 supervisors, only three (5.9\%) felt that it increased motivation, while $39(76.5 \%)$ believed it did not; the remaining nine (17.7\%) were undecided.

\section{Candidate support}

The survey investigated respondents' satisfaction with the LA's Associateship Regulations and Notes of Guidance. They were asked if these guidelines were easy to understand, relevant, accurate and comprehensive. The response was favourable overall, although almost a third of respondents $(31.4 \%)$ felt that the guidelines were difficult to understand. There were some significant differences between the groups: the levels of satisfaction were considerably lower amongst those who had defaulted or resigned, while those who had not yet 
submitted their applications also appeared to be less satisfied with the comprehensibility of the documentation provided.

The respondents were then asked to provide details of any aspects of the regulations and notes which they found to be particularly helpful or unhelpful. Seventy-eight respondents answered this question, although just a third of these (26 respondents) provided comments of a positive nature: for example, the documentation was variously described as 'informative, concise and easy to use', 'clearly written' and 'full and self-explanatory'. The Professional Development Proforma was regarded as a particularly valuable feature.

These positive comments, however, were outweighed by those of a critical nature. It should be emphasised here that critical comments were received not just from those groups whose levels of satisfaction with the documentation were relatively low (i.e. those who had not yet submitted and those who had defaulted/resigned), but were made throughout all four groups. The guidelines were described as: too long and complex; containing too much jargon; and adopting a 'pedantic', 'forbidding', 'stuffy' or 'aloof' tone. Respondents also indicated that the guidelines were lacking in detail when discussing candidates who: were changing their route to Associateship; did not work in a traditional library environment; were employed on short-term contracts; were changing jobs; had moved from part-time to full-time employment, or vice versa; or were taking a career break. Some respondents also felt that there was a distinct lack of detail on the ideal content of a PDR.

A number of respondents commented on other forms of candidate support provided by the LA. Nine respondents indicated that they had attended workshop events for Associateship candidates. While four of these described the events as useful and in many ways more helpful than the written guidelines, the remaining five respondents were less enthusiastic. They felt that the time in these workshops could have been used more effectively and that too little time was left at the end of the session to consider and discuss issues to be included in the candidates' PDRs. It was also felt that too much emphasis was placed on ensuring that the PDR covered the aims and objectives of the candidates' organisations, rather than on the personal development and progress of the individuals concerned. These respondents were also critical of the accessibility and frequency of the events, one pointing out that she had to wait for seven months before she could attend a workshop. Two respondents were also critical of the LA's telephone service to candidates.

Two respondents also discussed the Mailbase lis-la-charter e-mail discussion list, which provides a vehicle for candidates to discuss Chartering and other professional development 
matters. While both believed it to be a useful support mechanism, one was critical of the LA's occasional input .

\section{Supervisory support}

With the exception of the supervisors' group, respondents were asked to indicate their satisfaction with the support they had received from their supervisor (see Table 5). Just over $30 \%$ of the respondents did not have a supervisor, but of the 70 respondents who indicated that they did have a supervisor, $42(60 \%)$ had been satisfied or very satisfied with the support received. The proportion of supervised respondents who were satisfied or very satisfied was significantly higher amongst the group of recently elected candidates (72.7\%) than amongst those who had not yet submitted their applications (38.9\%); and notably five of the eight supervised candidates who had defaulted or resigned were dissatisfied with the support received.

\begin{tabular}{|l|c|c|c|c|c|c|c|c|}
\hline \multicolumn{10}{|l|}{ Table 5: Satisfaction with supervisory support } \\
\hline & $\begin{array}{c}\text { Recently } \\
\text { elected }\end{array}$ & \multicolumn{2}{c|}{$\begin{array}{c}\text { Not } \\
\text { submitted }\end{array}$} & \multicolumn{2}{c|}{$\begin{array}{c}\text { Defaulted/ } \\
\text { resigned }\end{array}$} & \multicolumn{2}{c|}{ Total } \\
\hline $\begin{array}{l}\text { Level of } \\
\text { satisfaction }\end{array}$ & No. & $\%$ & No. & $\boldsymbol{\%}$ & No. & $\%$ & No. & $\%$ \\
\hline Very satisfied & 16 & 27.6 & 3 & 10.0 & - & - & $\mathbf{1 9}$ & $\mathbf{1 8 . 6}$ \\
\hline Satisfied & 16 & 27.6 & 4 & 13.3 & 3 & 21.4 & $\mathbf{2 3}$ & $\mathbf{2 2 . 5}$ \\
\hline Not sure & 7 & 12.1 & 6 & 20.0 & 5 & 35.7 & $\mathbf{1 8}$ & $\mathbf{1 7 . 6}$ \\
\hline $\begin{array}{l}\text { Not satisfied at } \\
\text { all }\end{array}$ & 5 & 8.6 & 5 & 16.7 & 5 & 35.7 & $\mathbf{1 5}$ & $\mathbf{1 4 . 7}$ \\
\hline No supervisor & 14 & 24.1 & 12 & 40.0 & 1 & 7.1 & $\mathbf{2 7}$ & $\mathbf{2 6 . 5}$ \\
\hline Totals & 58 & 100 & 30 & 100 & 14 & 100 & $\mathbf{1 0 2}$ & $\mathbf{1 0 0}$ \\
\hline
\end{tabular}

Respondents were asked to explain why they were satisfied or dissatisfied with their supervisor. Most of the satisfied respondents indicated that their supervisor arranged regular meetings, provided encouragement and useful advice, discussed current issues and identified particular training needs. Some respondents, however, were satisfied because their supervisor was rarely seen and was not, therefore, constantly 'on their back' or 'interfering'.

The most common complaint amongst dissatisfied respondents concerned a lack of regular meetings; it was acknowledged that this was sometimes because of the supervisors' other work commitments, but in other cases was due to a lack of interest. A number of respondents explained that they were their supervisor's first candidate and that this had adversely affected 
the extent and quality of the support received. One respondent indicated that her supervisor provided only negative criticism; while another, on a temporary contract, received little assistance from her supervisor who, she believed, hoped that this work would be taken on by a new supervisor in the candidate's next workplace.

The special issues affecting the supervision of external candidates were investigated in an additional question directed at the supervisors' group. For most of the supervisors the difficulty in maintaining regular contact was the prime concern. However, a small number of supervisors also pointed to possible conflicts of interest with the candidate's employer: it was felt that an external supervisor would find it difficult to appreciate the requirements, pressures and politics of the candidate's organisation.

\section{Employer support}

Just under half $(49 \%)$ of the respondents felt that their employer had been supportive, although the perceived level of employer support was significantly higher amongst the group who had already achieved Associateship (58.6\%) than in the groups who had yet to submit $(40 \%)$ or who had defaulted/resigned (four of $14 ; 28.6 \%$ ). Most of the respondents who specified the nature of this support indicated that time off work had been given to attend suitable training courses and other professional development opportunities. Two respondents had received study leave in order to complete their PDRs. Two had had their application fees paid, while another respondent's employer had paid for the printing and binding of the PDR.

In contrast, 19 (18.6\%) of the respondents believed that their employer was not particularly supportive. A lack of employer support was more noticeable amongst the groups who had not yet submitted $(26.7 \%)$ or who had withdrawn from the process (six of $14 ; 42.9 \%$ ). Some felt that their employer adopted a somewhat passive role, and although registration was encouraged, little or no practical support (in terms of time or resources) was offered. Others questioned their employers' awareness of what the Chartership process actually means and entails.

Fifteen $(14.7 \%)$ of the respondents offered mixed opinions on their employers' support: generally these were individuals who had changed jobs during the course of the Chartership process and had found that their new employer was noticeably more or less supportive than their previous employer. Ten respondents $(9.8 \%)$ believed that the question was not really relevant, as they felt that the Chartership was effectively being conducted independently of 
their employer who had negligible input to the process. However, it should be noted that the majority of these came from the successfully completed group: for those facing difficulties in completion clearly employer support is an important factor.

\section{LA Continuing Professional Development Framework}

Respondents in all four groups were asked if they were aware of the LA's Continuing Professional Development Framework. Overall awareness was high (140 respondents, 91.5\%), with just 13 (8.5\%) respondents being unaware of the Framework. However, awareness was lower amongst the groups who had not yet submitted their applications $(80.0 \%)$ and those who had defaulted/resigned (78.6\%).

The 140 respondents who were aware of the Framework were then asked if they had actually used it, for supporting their progress to Associateship or for other CPD purposes. Just 39 individuals (27.9\%) had used the Framework, with the defaulted/resigned group indicating that they had used it the least (two of $11 ; 18.2 \%$ ).

The 39 respondents who had used the Framework were asked to comment on its usefulness. The majority of these respondents $(23 ; 59.0 \%)$ provided comments that were positive in nature:

"It was useful in instilling in me the ethic to constantly review development activities and to plan future learning goals and objectives in the light of professional experience."

"Very useful to plan areas of potential development - holistically."

"Found it quite useful for target setting, thinking about training for improvement and promotion long-term."

Just three respondents produced comments that were wholly critical, one describing the Framework as "almost unreadable, badly packaged, badly presented and too much effort to plough through after a day's work".

Meanwhile, the 101 respondents who were aware of the Framework but who had not used it were asked to provide reasons as to why it had not been used (see Table 6). 


\begin{tabular}{|c|c|c|c|c|c|c|c|c|c|c|}
\hline \multirow{3}{*}{\begin{tabular}{l|} 
Table 6: Reasons $\boldsymbol{f}$ \\
\\
Reason
\end{tabular}} & \multirow{2}{*}{\multicolumn{2}{|c|}{$\begin{array}{c}\text { for not using } L \\
\begin{array}{c}\text { Recently } \\
\text { elected }\end{array}\end{array}$}} & \multirow{2}{*}{\multicolumn{2}{|c|}{ 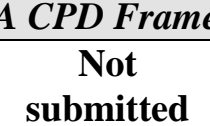 }} & & & & & & \\
\hline & & & & & \multicolumn{2}{|c|}{$\begin{array}{l}\text { Defaulted/ } \\
\text { resigned }\end{array}$} & \multicolumn{2}{|c|}{ Supervisors } & \multicolumn{2}{|c|}{ Total } \\
\hline & No. & $\%$ & No. & $\%$ & No. & $\%$ & No. & $\%$ & No. & $\%$ \\
\hline $\begin{array}{l}\text { Not appropriate } \\
\text { for my needs }\end{array}$ & 14 & 35.0 & 9 & 50.0 & 3 & 33.3 & 3 & 8.8 & 29 & 28.7 \\
\hline $\begin{array}{l}\text { Employer has } \\
\text { own scheme/ } \\
\text { framework }\end{array}$ & 5 & 12.5 & 1 & 5.6 & - & - & 14 & 41.2 & 20 & 19.8 \\
\hline $\begin{array}{l}\text { Devised my } \\
\text { own framework }\end{array}$ & 6 & 15.0 & - & - & 1 & 11.1 & 2 & 5.9 & 9 & 8.9 \\
\hline Lack of time & - & - & - & - & - & - & 10 & 29.4 & 10 & 9.9 \\
\hline Lack of interest & - & - & 2 & 11.1 & 2 & 22.2 & 1 & 2.9 & 5 & 5.0 \\
\hline $\begin{array}{l}\text { Didn't think to } \\
\text { use it }\end{array}$ & 4 & 10.0 & 2 & 11.1 & - & - & - & - & 6 & 5.9 \\
\hline $\begin{array}{l}\text { Never received } \\
\text { a copy }\end{array}$ & - & - & - & - & - & - & 1 & 2.9 & 1 & 1.0 \\
\hline $\begin{array}{l}\text { Plan to use it in } \\
\text { future }\end{array}$ & - & - & - & - & - & - & 1 & 2.9 & 1 & 1.0 \\
\hline Don't know & 1 & 2.5 & 1 & 5.6 & - & - & - & - & 2 & 2.0 \\
\hline No response & 10 & 25.0 & 3 & 16.7 & 3 & 33.3 & 2 & 5.9 & 18 & 17.8 \\
\hline Totals & 40 & 100 & 18 & 100 & 9 & 100 & 34 & 100 & 101 & 100 \\
\hline
\end{tabular}

Just under $29 \%$ of these respondents simply indicated that the LA Framework was not relevant or appropriate for their particular needs; while almost $20 \%$ explained that their employers had their own professional development framework, or a career review or appraisal scheme which could be regarded as a suitable equivalent. A small number of respondents had devised their own framework. Interestingly, a substantial proportion (29.4\%) of the supervisors' group felt that a lack of time had prevented them from using the LA Framework.

\section{Support scheme for Route B candidates}

The next section of the survey focused on a new support scheme for Route B candidates, developed by the Professional Qualifications Department and the Personnel Training and Education Group of the LA, and based on the development of a network of volunteer mentors. The 51 respondents in the supervisors' group were asked if they were aware of the introduction of this scheme. The response was evenly split, with 26 respondents (51\%) aware of the scheme, and 25 (49\%) unaware of its existence.

Supervisors, as well as those respondents who had not yet completed their application and those who had resigned/defaulted, were asked if they felt that this mentoring scheme would 
be beneficial (see Table 7). The majority (69.5\%) felt that such a scheme would be beneficial, although almost $18 \%$ were undecided, largely because they were unfamiliar with the scheme. The Route B candidates who had not yet submitted were particularly positive, with $75 \%$ believing the scheme would prove beneficial.

\begin{tabular}{|l|c|c|c|c|c|r|r|r|}
\hline Table 7: Opinions of new support scheme for Route B candidates \\
\hline & $\begin{array}{c}\text { Not } \\
\text { submitted }\end{array}$ & $\begin{array}{c}\text { Defaulted/ } \\
\text { resigned }\end{array}$ & \multicolumn{2}{|c|}{ Supervisors } & \multicolumn{2}{|c|}{ Total } \\
\hline & No. & $\%$ & No. & $\%$ & No. & $\%$ & No. & \multicolumn{1}{c|}{$\%$} \\
\hline Beneficial & 20 & 66.7 & 8 & 57.1 & 38 & 74.5 & $\mathbf{6 6}$ & $\mathbf{6 9 . 5}$ \\
\hline Not beneficial & - & - & 2 & 14.3 & 1 & 2.0 & $\mathbf{3}$ & $\mathbf{3 . 2}$ \\
\hline Undecided & 5 & 16.7 & 2 & 14.3 & 10 & 19.6 & $\mathbf{1 7}$ & $\mathbf{1 7 . 9}$ \\
\hline No response & 5 & 16.7 & 2 & 14.3 & 2 & 3.9 & $\mathbf{9}$ & $\mathbf{9 . 5}$ \\
\hline Totals & 30 & 100 & 14 & 100 & 51 & 100 & $\mathbf{9 5}$ & $\mathbf{1 0 0}$ \\
\hline
\end{tabular}

The respondents who felt that the mentoring scheme would be beneficial were then asked to provide reasons for their answer. Several made the point that Route B candidates are often solo librarians working in small organisations and, therefore, prone to professional isolation; it was felt that the mentoring scheme would help to overcome this problem, particularly when it involves individuals who have recently experienced the Chartership process. Others simply felt that any form of additional support would be useful. Some respondents insisted, however, that any such scheme should not be made compulsory for Chartership candidates. A small number pointed out that mentoring for staff development purposes was already being used successfully within their organisations, on a formal or informal basis.

It was suggested by some respondents that a mentoring scheme might also be applied to Route A candidates. One respondent felt that some Route A supervisors do not find themselves in that position by choice, and can therefore be less than enthusiastic about the process. This respondent felt, therefore, that the additional input of voluntary mentors who want to become involved would be more beneficial to candidates. Another respondent, who had acted as a PDR scrutineer, also felt that mentors might be needed to 'pick up the pieces' following poor Chartership supervision and training.

\section{Supervising Candidates}

The 51 supervisors were asked a set of questions relating to the supervision of candidates. Thirty-nine respondents (76.5\%) had supervised (or were supervising) internal candidates only, while $10(19.6 \%)$ had experience of supervising both internal and external candidates. 
$20(39.2 \%)$ of the respondents had supervised a single candidate; while a further 18 (35.3\%) had supervised between two and five candidates. One respondent had overseen the applications of 20 candidates to date.

When asked if this supervisory role was outlined within their job description, less than a quarter of the supervisors $(12 ; 23.5 \%)$ indicated that it was listed formally as part of their duties; and when asked if they had been trained as a supervisor, just nine (17.6\%) of the respondents indicated that they had received any formal instruction.

The group was also asked why they had decided to become supervisors. As has already been indicated, 12 respondents had the supervisory role specified within their job description, generally as part of an overall responsibility for staff development and training. A further eight respondents indicated that candidate supervision, although not specifically listed in their job descriptions, was implicitly part of their duties. Nine respondents had been approached by particular prospective candidates, while four had found that they were the only individuals within their organisations who were qualified to become a supervisor. However, the largest proportion (17 respondents) indicated that becoming a supervisor was due mostly to a commitment to the library and information profession and a desire to "put something back into the profession'.

The supervisors were also asked to indicate the type of training programme that was used by their Chartership candidates (see Table 8). Nearly three quarters had developed their own training programme or used a combination of their own programme and that of their institution, while only a quarter has been able to rely fully on an institutional programme.

\begin{tabular}{|l|c|c|}
\hline \multicolumn{3}{|l|}{$\begin{array}{l}\text { Table 8: Type of training programme used by } \\
\text { Chartership supervisors }\end{array}$} \\
\hline $\begin{array}{l}\text { Type of training } \\
\text { programme }\end{array}$ & No. & $\%$ \\
\hline Institutional training & 12 & 23.5 \\
\hline Own training programme & 21 & 41.2 \\
\hline Combination of both & 17 & 33.3 \\
\hline No response & 1 & 2.0 \\
\hline Totals & 51 & 100 \\
\hline
\end{tabular}

Finally, the supervisors were asked about their satisfaction with the support provided by the Supervisors' Liaison Network. This network was established in 1992 and is designed to provide assistance, advice and training opportunities to Chartership supervisors. The majority $(64.7 \%)$ of the supervisors had never used the Network. Just 16 of the supervisors had used 
the Network, and of these, 11 were satisfied or very satisfied with the assistance received, four were undecided and only one respondent expressed dissatisfaction with the support received.

\section{Membership of Library Association}

All groups were asked to indicate, from a list of six possible reasons, why they had joined the Library Association (see Table 9).

\begin{tabular}{|c|c|c|c|c|c|c|c|c|c|c|}
\hline Table 9: Reasons for joinin & & & & & & & & & & \\
\hline & $\begin{array}{r}\text { Rec } \\
\text { ele } \\
(581 \\
\end{array}$ & & $\begin{array}{r}1 \\
\text { sub } \\
\text { (30 } \\
\end{array}$ & $\begin{array}{l}\text { ot } \\
\text { itted } \\
\text { esps) }\end{array}$ & $\begin{array}{c}\text { Defe } \\
\text { res } \\
(14\end{array}$ & $\begin{array}{l}\text { Itted/ } \\
\text { sned } \\
\text { esps) }\end{array}$ & $\begin{array}{l}\text { Supe } \\
\text { (51 }\end{array}$ & $\begin{array}{l}\text { visors } \\
\text { esps) }\end{array}$ & & $\begin{array}{l}\text { als } \\
53 \\
\text { ps) } \\
\end{array}$ \\
\hline Reason & No. & $\%$ & No. & $\%$ & No. & $\%$ & No. & $\%$ & No. & $\%$ \\
\hline Job vacancies & 52 & 89.7 & 27 & 90.0 & 13 & 92.9 & 35 & 68.6 & 127 & 83.0 \\
\hline Become chartered & 48 & 82.8 & 21 & 70.0 & 8 & 57.1 & 47 & 92.2 & 124 & 81.0 \\
\hline $\begin{array}{l}\text { Improve awareness of current } \\
\text { issues }\end{array}$ & 41 & 70.7 & 23 & 76.7 & 9 & 64.3 & 37 & 72.5 & 110 & 71.9 \\
\hline Attend courses & 15 & 25.9 & 11 & 36.7 & 2 & 14.3 & 20 & 39.2 & 48 & 31.3 \\
\hline Make contacts & 15 & 25.9 & 10 & 33.3 & 1 & 7.1 & 20 & 39.2 & 46 & 30.1 \\
\hline $\begin{array}{l}\text { Membership benefits (e.g. } \\
\text { discounts) }\end{array}$ & 6 & 10.3 & 3 & 10.0 & 1 & 7.1 & 3 & 5.9 & 13 & 8.5 \\
\hline
\end{tabular}

There were some significant differences between the groups. For example, obtaining details of job vacancies was far less important to the supervisors $(68.6 \%)$ than to the other respondents. Vacancies information was also less crucial to those aged 45-54 (69.4\%) than to those aged 30-44 (85.7\%) or the under-30s (97.5\%); and less important to those who had been qualified in LIS for over 10 years $(70 \%)$ when compared with those who had been qualified for 3-4 years (96.9\%) or for 5-6 years (92.9\%). Joining the LA to become chartered appeared to be less important for those candidates who had defaulted/resigned (57.1\%) or who had not yet completed the process (70\%) than for the recently elected Associates (82.8\%) and the supervisors $(92.2 \%)$. However, it is important to note that despite withdrawing from the process personally, a majority in this group still felt that the opportunity to become an Associate had been a motivating factor in joining the LA, suggesting that they still see this as a desirable end result despite having failed to achieve it themselves. 
A number of respondents provided other reasons for joining the LA: to feel part of the LIS profession (nine respondents); because it was 'expected', generally when starting as an LIS student (8).

\section{Importance of Associateship}

All respondents were also asked to indicate, from a list of six, the advantages of Associateship. Chartered status was the most popular response $(76.5 \%)$, with professional recognition also being cited by over $60 \%$ of the sample. Just over $30 \%$ felt that a salary increase was an important consequence of achieving Associateship, but less than $16 \%$ believed that there was an element of prestige attached to the qualification. Eight individuals (none of whom had yet attained Associateship) believed that the qualification had no advantages whatsoever.

There were again some interesting, significant variations between groups. Chartered status was regarded as less of an advantage by those who had withdrawn from the process (50\%). Professional recognition was cited more frequently by the supervisors $(84.3 \%)$ than by the other groups; and also more frequently by those aged 45 and over $(77.8 \%)$ than by the under45s (54.6\%). No-one in the defaulted/resigned group believed an enhanced career to be a benefit of Associateship. A salary increase was regarded more favourably by those candidates who had yet to complete the process (50\%) than by the other groups; and by those respondents working in public libraries (37.0\%), when compared with those in academic libraries (18.9\%). Interestingly, prestige was more highly regarded as an advantage by male respondents $(29.4 \%)$ than by females $(11.8 \%)$.

All four groups were also asked if they believed that it was important for information professionals to be chartered (see Table 10). A slight majority (56.2\%) was certain that it was important, although almost $27 \%$ were unsure. A smaller but substantial proportion (17\%) believed it to be unimportant. The supervisors' group appeared to be more convinced of its importance $(80.4 \%)$ than the other groups; as did those aged 45 and over (68.9\%) when compared with the under-45s (50.9\%). 


\begin{tabular}{|l|c|c|c|c|c|c|c|c|c|c|}
\hline Table 10: Importance of information professionals being chartered \\
\hline & $\begin{array}{c}\text { Recently } \\
\text { elected }\end{array}$ & \multicolumn{2}{c|}{$\begin{array}{c}\text { Not } \\
\text { submitted }\end{array}$} & $\begin{array}{c}\text { Defaulted/ } \\
\text { resigned }\end{array}$ & \multicolumn{2}{|l|}{ Supervisors } & \multicolumn{2}{|c|}{ Total } \\
\hline & No. & $\%$ & No. & $\%$ & No. & $\%$ & No. & \% & No. & $\%$ \\
\hline Important & 33 & 56.9 & 11 & 36.7 & 1 & 7.1 & 41 & 80.4 & $\mathbf{8 6}$ & $\mathbf{5 6 . 2}$ \\
\hline Not important & 9 & 15.5 & 5 & 16.7 & 7 & 50.0 & 5 & 9.8 & $\mathbf{2 6}$ & $\mathbf{1 7 . 0}$ \\
\hline Not sure & 16 & 27.6 & 14 & 46.7 & 6 & 42.9 & 5 & 9.8 & $\mathbf{4 1}$ & $\mathbf{2 6 . 8}$ \\
\hline Totals & 58 & 100 & 30 & 100 & 14 & 100 & 51 & 100 & $\mathbf{1 5 3}$ & $\mathbf{1 0 0}$ \\
\hline
\end{tabular}

In an open question, the respondents were also asked to provide reasons for their answer. The responses of those who felt that the Chartership was important followed five main recurring themes, that Chartership:

- provides the LIS profession with a recognised quality standard;

- illustrates an interest in and a commitment to the wider LIS profession;

- helps new professionals to focus on their own personal development;

- provides an avenue to salary increases, promotion and better jobs; and

- raises the profile and improves the image of the LIS profession, amongst the general public and other professions

Those who believed that Chartership was unimportant were, unsurprisingly, more sceptical about the process. It was felt that attaining Chartered status simply demonstrated that the candidates could write a report. One respondent, pointing to the $96 \%$ success rate of the Chartership process, believed that it required little more than persistence. Some respondents suggested that a Charter was now less of a requirement amongst prospective employers and that the entire process was therefore anachronistic. The respondents who were undecided about the Chartership's importance tended to echo the comments made above, particularly that fewer employers now insist that a Charter be held.

The next question sought to obtain further information about employers' perceptions of Chartership. With the exception of the supervisors' group, respondents were asked how important Chartership was considered to be by their employer. Just over a quarter of respondents felt that their employer regarded a Charter as essential or very important, while another $27.5 \%$ believed it to be quite important. Over $40 \%$ believed that their employer placed no importance on Chartership; interestingly, this figure was significantly higher amongst those respondents who had withdrawn from the Chartership process (78.6\%). 
There were also some interesting differences when comparing the responses of those who worked in the public sector with those who worked in the academic sector: $50 \%$ of the public librarians felt that their employer regarded a Charter as essential or very important, compared with just $14.3 \%$ of the academic librarians; and in contrast $19.2 \%$ of those in public libraries believed it to be unimportant to their employer, compared with $48.6 \%$ of those in the academic sector.

The 58 respondents who had recently been elected as Associates were asked if their achievement had brought any financial reward from their employer. Twenty (34.5\%) of the respondents had received some form of financial reward: 17 were given an increase in salary, one was given a one-off bonus, while the remaining two respondents did not specify the nature of their reward.

\section{Importance of Formal Qualifications in LIS}

With the exception of the supervisors' group, respondents were asked how important they felt a formal qualification in LIS was in terms of professional development. Just under $70 \%$ of the respondents believed a qualification to be essential or very important, while less than $5 \%$ felt that it was unimportant.

The same respondents were asked which they felt was more important in terms of professional development - a formal academic qualification in LIS or professional recognition (see Table 11). Almost $40 \%$ felt that an LIS qualification was more important, while less than $7 \%$ believed professional recognition to be of greater value. A slight majority of almost $54 \%$ favoured a combination of the two. Compared with the other two groups, a far higher proportion of those who had defaulted/resigned (11 of 14; 78.6\%) believed an academic qualification to be the more important asset.

\begin{tabular}{|c|c|c|c|c|c|c|c|c|}
\hline \multicolumn{9}{|c|}{$\begin{array}{l}\text { Table 11: Which is more important - LIS qualification or professional } \\
\text { recognition? }\end{array}$} \\
\hline & \multicolumn{2}{|c|}{$\begin{array}{c}\text { Recently } \\
\text { elected }\end{array}$} & \multicolumn{2}{|c|}{$\begin{array}{c}\text { Not } \\
\text { submitted }\end{array}$} & \multicolumn{2}{|c|}{$\begin{array}{l}\text { Defaulted } \\
\text { /resigned }\end{array}$} & \multicolumn{2}{|c|}{ Total } \\
\hline & No. & $\%$ & No. & $\%$ & No. & $\%$ & No. & $\%$ \\
\hline Formal qualification & 17 & 29.3 & 11 & 36.7 & 11 & 78.6 & 39 & 38.2 \\
\hline Professional recognition & 4 & 6.9 & 2 & 6.7 & 1 & 7.1 & 7 & 6.9 \\
\hline Combination of both & 37 & 63.8 & 16 & 53.3 & 2 & 14.3 & 55 & 53.9 \\
\hline No response & - & - & 1 & 3.3 & - & - & 1 & 0.9 \\
\hline Totals & 58 & 100 & 30 & 100 & 14 & 100 & 102 & 100 \\
\hline
\end{tabular}


In an open question, the same respondents were asked to provide reasons for their answer. Those respondents who felt that an LIS degree was more important explained that such a qualification provides a basic grounding in information work and is therefore a fundamental requirement for anyone wishing to enter the field of LIS and to subsequently gain professional recognition. Of the seven respondents who felt professional recognition was the more important asset, just three provided reasons for their answer: two of these felt that they had gained considerably more practical knowledge during their Chartership training than they had at library school; while the other, currently unemployed, felt that theirs had not been a particularly successful career, despite obtaining a good LIS qualification.

Meanwhile, the respondents who felt that a combination of academic qualifications and professional recognition was the preferred option indicated that the two assets effectively complement each other - "experience and expertise are as necessary as a piece of paper" and that striving for professional recognition allows the individual to build upon their initial qualification. The point was again made that obtaining a Charter allowed greater opportunities for progression in the LIS field and, in some cases, pursuing further academic qualifications: for example, one respondent was required to obtain his Charter before being accepted for an MA course.

The next two questions examined the respondents' perceptions of their employers' regard for both academic qualifications and professional recognition. The vast majority (86.2\%) of respondents were of the opinion that their employers regarded academic qualifications as essential or important. Just three individuals believed that their employers disregarded academic qualifications.

The employers' regard for professional recognition, however, was perceived to be somewhat lower: just over $45 \%$ believed it to be essential or important, while almost a quarter $(22.5 \%)$ felt it was unimportant. Reinforcing the finding of an earlier, similar question, professional recognition was seen as far more important in public libraries than in academic libraries: $69.2 \%$ of those employed in public libraries felt it was regarded as essential or important, compared with $31.5 \%$ of those in academic libraries; while $7.7 \%$ of the public library sector believed it to be unimportant, compared with $31.4 \%$ of academic librarians. 


\section{Continuing Professional Development}

The final section of the survey investigated the respondents' views on continuing professional development. The four groups were initially asked if they were interested in their own CPD. The vast majority (93.5\%) declared an interest in their own CPD, with only nine individuals (four of them in the defaulted/resigned group) having no interest. It should be pointed out that the three supervisors who were uninterested in their own CPD were all rapidly approaching retirement age and felt that CPD was perhaps now of little relevance to them.

The 143 respondents who declared an interest in their own CPD were then asked how important it was for their careers. CPD was regarded as important or very important by $85.4 \%$ of the respondents, with just five individuals (again older respondents) believing it to be unimportant. Indeed, the proportion of those aged under 45 who felt CPD was very important (46.3\%) was considerably higher than of those aged 45 or over $(28.9 \%)$.

The entire sample was provided with a list of nine professional development activities and asked to indicate which they were currently undertaking. The response is shown in Table 12. The most popular activity was reading professional literature $(85 \%)$, while over half of the sample in each case was involved in external seminars and conferences, networking with colleagues and internal training courses. A small proportion (4.6\%) was looking to obtain the LA Fellowship. These findings can be compared with those of a previous study of UK LIS professionals, conducted by MacDougall et al in 1990 [37], which established that recent CPD activities had included short courses (68\% of respondents), in-service training (66\%), discussion fora/seminars (54\%), conferences (38\%), lectures (17\%), extensive courses $(7 \%)$, and courses for study (6\%). Another earlier study, by Whitehall et al [38], revealed that $92 \%$ of UK academic librarians and 'more than half' of UK public librarians read LIS research journals. Roberts and Konn [39] have noted that, while some authors have stressed the importance of reading professional literature as part of CPD, the Medical Library Association does not award points for this activity in its Academy of Health Information Professionals programme. 


\begin{tabular}{|c|c|c|c|c|c|c|c|c|c|c|}
\hline \multicolumn{11}{|c|}{ Table 12: Current professional development activities } \\
\hline & \multicolumn{2}{|c|}{$\begin{array}{l}\text { Recently } \\
\text { elected } \\
\text { (58 resps) }\end{array}$} & \multicolumn{2}{|c|}{$\begin{array}{c}\text { Not } \\
\text { submitted } \\
\text { (30 resps) }\end{array}$} & \multicolumn{2}{|c|}{$\begin{array}{l}\text { Defaulted/ } \\
\text { resigned } \\
(14 \text { resps })\end{array}$} & \multicolumn{2}{|c|}{$\begin{array}{c}\text { Supervisors } \\
\text { (51 resps) }\end{array}$} & \multicolumn{2}{|c|}{$\begin{array}{c}\text { Totals } \\
(153 \\
\text { resps }) \\
\end{array}$} \\
\hline Activity & No. & $\%$ & No. & $\%$ & No. & $\%$ & No. & $\%$ & No. & $\%$ \\
\hline $\begin{array}{l}\text { Reading professional } \\
\text { literature }\end{array}$ & 48 & 82.8 & 27 & 90.0 & 10 & 71.4 & 45 & 88.2 & 130 & 85.0 \\
\hline $\begin{array}{l}\text { External seminars/ } \\
\text { conferences }\end{array}$ & 31 & 53.4 & 19 & 63.3 & 7 & 50.0 & 40 & 78.4 & 97 & 63.4 \\
\hline Networking with colleagues & 32 & 55.2 & 19 & 63.3 & 6 & 42.9 & 35 & 68.6 & 92 & 60.1 \\
\hline Internal training by employer & 36 & 62.1 & 19 & 63.3 & 5 & 35.7 & 28 & 54.9 & $\mathbf{8 8}$ & $\mathbf{5 7 . 5}$ \\
\hline $\begin{array}{l}\text { Professional involvement } \\
\text { (e.g. committee work) }\end{array}$ & 18 & 31.0 & 12 & 40.0 & 4 & 28.6 & 25 & 49.0 & 59 & 38.6 \\
\hline Electronic discussion lists & 19 & 32.8 & 9 & 30.0 & 5 & 35.7 & 21 & 41.2 & 54 & 35.3 \\
\hline $\begin{array}{l}\text { Studying for a further } \\
\text { academic qualification }\end{array}$ & 7 & 12.1 & 4 & 13.3 & 3 & 21.4 & 10 & 19.6 & 24 & 15.7 \\
\hline $\begin{array}{l}\text { Studying for a further } \\
\text { professional/vocational qualif }\end{array}$ & 4 & 6.9 & 3 & 10.0 & 2 & 14.3 & 4 & 7.8 & 13 & 8.5 \\
\hline LA Fellowship & 3 & 5.2 & & - & - & - & 4 & 7.8 & 7 & 4.6 \\
\hline
\end{tabular}

There were some interesting inter-group and demographic differences in the response to this question. Internal training courses were being undertaken by a larger proportion of females (63.0\%) than males (38.2\%). External seminars and conferences were being attended by a greater proportion of supervisors (78.4\%) and of those aged 45-54 (76.3\%), perhaps reflecting the advantages such seniority brings. Professional literature was being read by a higher proportion of public librarians (95.7\%) than academic librarians (77.4\%) (this is in contrast to the findings of Whitehall et al described above); but electronic discussion lists were used more in the academic sector (60.4\%) than in public libraries (8.7\%), presumably because of a greater level of connectivity.

Respondents were asked if they felt that CPD should be compulsory. Opinions were mixed, with $41.2 \%$ believing it should be compulsory and $54.2 \%$ holding the opposite view. Roberts and Konn have pointed out that such a difference of opinion has been typical of other professions considering mandatory CPD, but have suggested that continuing membership of the Library Association should be: 'dependent upon systematic efforts to maintain and improve competence. Such a requirement should be both mandatory and demonstrable in its satisfaction' [39].

Most of the survey respondents who believed that CPD should be compulsory stated that the library and information profession is a rapidly changing one, where knowledge and skills can quickly become out-of-date: they therefore believed that CPD is essential to maintain the 
quality and currency of library and information services. Some respondents pointed out that other professions, such as the legal and medical professions, have compulsory CPD and felt that the information profession should follow suit.

Meanwhile, those respondents who felt that CPD should not be compulsory offered a variety of reasons for their answer. Firstly, several believed in the individual's freedom of choice, and emphasised that different people will have different levels of ambition. It was also pointed out that some individuals find it difficult enough to balance current work commitments with other domestic pressures without having to deal with additional workrelated activities. Several also felt compulsion of any kind to be counter-productive, that compulsory CPD would add to existing pressures and create resentment amongst employees. Some respondents questioned how the results of compulsory CPD might be measured and what penalties could be imposed for not participating in this compulsory activity. However, there were a number of respondents who, whilst believing that CPD should not be compulsory, felt that it should be strongly encouraged, perhaps with greater rewards attached.

With the exception of the supervisors' group, respondents were asked for their thoughts on how their employers viewed CPD. Just over 38\% felt that their employer regarded CPD as being necessary all the time, while a slightly smaller proportion (34.3\%) felt that it was regarded as necessary only on occasions. Just 11 respondents (10.8\%) believed that CPD was regarded as unnecessary within their organisation. This appears more positive than the findings of a previous study, by MacDougall et al [37], which indicated that $20 \%$ of LIS professionals in the UK believed that their employers gave CPD and training for professional staff a low priority.

In the final question of the survey, the same respondents were asked for their feelings on how their employers regarded responsibility for CPD (see Table 13). Just under $40 \%$ of respondents felt that their employer believed that CPD should be the responsibility of the individual employee; while only two individuals felt that their employer would take sole responsibility for professional development. A slight majority (53.9\%) believed that responsibility for CPD would lie both with the employer and the employee. Professional LIS bodies certainly appear to believe in a shared responsibility. The Scottish Library and Information Council, for example, states that 'employers and employees share responsibility for CPD: employers should develop sound CPD programmes and encourage their staff to take part; employees should acknowledge their need to learn and be willing to do so' [40]. 


\begin{tabular}{|c|c|c|c|c|c|c|c|c|}
\hline \multicolumn{9}{|c|}{ Table 13: Employers' feelings on responsibility for CPD } \\
\hline & \multicolumn{2}{|c|}{$\begin{array}{c}\text { Recently } \\
\text { elected }\end{array}$} & \multicolumn{2}{|c|}{$\begin{array}{c}\text { Not } \\
\text { submitted }\end{array}$} & \multicolumn{2}{|c|}{$\begin{array}{c}\text { Defaulted/ } \\
\text { resigned }\end{array}$} & \multicolumn{2}{|c|}{ Total } \\
\hline Responsibility for CPD & No. & $\%$ & No. & $\%$ & No. & $\%$ & No. & $\%$ \\
\hline Responsibility of individual & 27 & 46.6 & 8 & 26.7 & 5 & 35.7 & 40 & 39.2 \\
\hline Responsibility of employer & 1 & 1.7 & - & - & 1 & 7.1 & 2 & 2.0 \\
\hline Combination of both & 28 & 48.3 & 20 & 66.7 & 7 & 50.0 & 55 & 53.9 \\
\hline Don't know & 2 & 3.4 & - & - & 1 & 7.1 & 3 & 2.9 \\
\hline Unemployed - not relevant & - & - & 2 & 6.7 & - & - & 2 & 2.0 \\
\hline Total & 58 & 100 & 30 & 100 & 14 & 100 & 102 & 100 \\
\hline
\end{tabular}

\section{Conclusions}

A search of the professional literature indicates that there have been few studies of professional LIS qualifications and/or CPD, either in the UK or internationally, despite the increasing importance of these topics. The results of the literature search suggest that there is little consensus on the appropriateness of 'certification-based' professional qualifications and on the form that these should take. There does, however, appear to be broader agreement on the value of CPD.

The survey response rate was a valid 38.3\% (158 respondents): however, results may be biased in favour of the attitudes of recently enrolled Associates (58\%) and supervisors (51\%) rather than candidates not yet completed (30\%) and those who had dropped out of the process (14\%). Follow up interviews with withdrawn and not yet completed candidates helped to provide a more rounded picture of attitudes and experience amongst all of the target research groups.

The respondent group reflected a representative sample of the research target, coming from a range of employment sectors, with academic and public library sectors predominant. Respondents were almost equally split between those that had an undergraduate LIS qualification (44.4\%) and those with a postgraduate LIS qualification (49.7\%).

Whether the candidate had opted for Route A or Route B modes had little impact upon success. There was a slight tendency for Route B candidates to continue in registration for an extended period, while Route A candidates were more likely to withdraw if they had not submitted within a certain period. While for the majority completion takes less than two years, there remains a considerable proportion (37.9\%) of candidates who take over two years 
to complete successfully. This would suggest that to introduce too tight a deadline would discourage a number of candidates who are presently succeeding (albeit slowly).

For all those not yet complete or who had defaulted a combination of factors had affected progress, the most notable of which were: conflicting pressures, lack of time, loss of interest and poor supervision. These data would suggest that it is not the LA infrastructure that requires attention, but rather that heightened promotion of the benefits of Associateship is required directed at both candidates and employers. Those still to submit tended to feel discouraged and negative about what they saw as their poor progress: some form of reinforcement or encouragement at a fixed point in the process would be useful, where for example after three years in registration, candidates might be required to report on progress and present a schedule for completion with self imposed deadlines built in.

Respondents were uncertain whether unlimited time for completion was advantageous or not, with the exception of supervisors who tended to feel that the lack of a deadline led to decreased motivation (76.5\%) and encouraged procrastination (92.3\%). Given supervisors' wider experience, this is an interesting finding: however, the fact that a small but noticeable number do successfully complete would again support the contention that too tight a deadline would be inappropriate.

Most respondents appeared to feel that the LA's Guidelines were satisfactory, although almost a third felt that they were difficult to understand. However, further open comments (52 respondents) found fault with the tone taken by the LA Professional Qualifications Department and the lack of guidance offered in specific, individual approaches in training sessions for candidates. Other forms of support elicited criticism in interview with not yet complete and withdrawn candidates. Such comment would suggest that a more responsive and 'friendly' service might be provided. The LA Guidelines should acknowledge likely influential factors in candidates' completion rates: support and advice should be provided indicating ways in which predicted barriers might be overcome.

The quality of support provided by the candidate's supervisor would appear to have a material impact upon success. Satisfaction with supervision was significantly higher amongst those recently elected $(72.7 \%)$ than amongst those not yet submitted (38.9\%): equally higher numbers of those without a supervisor had not yet completed their application. Candidates merited regular meetings with supervisors and feeling that their supervisor was expert, experienced and interested. 
Those candidates still to submit or withdrawn tended to have received less support from employers, while those that had successfully completed reported more positive experiences or felt that employer support was not relevant. Employers may also be influential in addressing problems relating to lack of time and conflicting pressures.

Respondents were not familiar with the detail of the LA mentoring scheme for Route $\mathrm{B}$ candidates. Route B respondents were particularly positive about this innovation, 75\% believing that this would prove beneficial in overcoming the common problem of isolation. A number of respondents felt that a pool of mentors should be made available additionally to Route A candidates, in order to overcome candidate isolation and poor supervision.

A substantial proportion of supervisors were relatively inexperienced in the role, over half having only supervised one or two candidates: this finding reinforces the contention that a pool of experienced mentors would be beneficial. In the majority of instances supervisors were either solely responsible for devising the training programme or amended an existing institutional programme. The majority of supervisors (64.7\%) had not used the Supervisors' Liaison Network: of those that had used the Network the majority were satisfied with the assistance received. These results reinforce the importance of the supervisor and the extent to which the quality of the supervisory input may be variable, working frequently as they do in isolation and without a great deal of prior experience.

Respondents valued membership of the LA because of: access to vacancies information (83\%); the opportunity to become Chartered $(81 \%)$; and keeping up to date with issues of current concern. The perceived significance of Associateship was far greater amongst the recently elected $(82.8 \%)$ and supervisors $(92.2 \%)$ than for those still to complete (70\%) and the withdrawn (57.1\%). However, it is important to note that, despite withdrawing from the process personally, a majority in this group still felt that the opportunity to become an Associate had been a motivating factor in joining the LA.

Associateship was seen as advantageous largely in that it conferred chartered status and professional recognition: fewer respondents felt that it had, or was likely to, lead to an enhanced career, a salary increase or prestige. In all cases, the recently elected and supervisors were more conscious of the potential advantages of Associateship. These data would further support the conclusion that the LA should make further efforts to promote the concept of Associateship, through, for example, a brochure or poster outlining the potential advantages of achieving Associate status, such as opportunities for career progression, flexibility and improved evaluative and analytical skills. 
Only a slight majority felt certain that it was important for information professionals to be chartered (56.2\%), while $17 \%$ felt that it was unimportant and a surprisingly high $27 \%$ were unsure. Respondents felt Associateship to be important in providing a quality standard, demonstrating commitment to the profession, helping new professionals to focus on their continuing development, providing an avenue to career progression and raising the profile and image of the profession. Some respondents felt that the process of attaining chartered status was undemanding, did not relate to professional capacity and was of less interest to employers than it had been in the past.

Surprisingly small numbers of respondents felt that their employer regarded Associateship to be essential $(9.8 \%)$ or very important $(15.7 \%)$ : a substantial proportion felt it was not important (40.2\%). This finding is highly significant in that without support from employers candidates are less likely to complete successfully. Further research into employers' attitudes to Associateship is urgently required in order to test whether the candidates' perceptions outlined in this report are in fact valid.

Just under $70 \%$ of respondents believed a qualification to be essential or very important to their professional development. The majority believed a combination of educational qualification and professional charter to be the preferred option recognising a natural complementarity between the two assets.

Generally employers were felt more likely to merit academic qualifications (86.2\%) rather than professional recognition $(45.1 \%)$. Professional recognition was felt by respondents to be far more important in the public library sector $(69.2 \%)$ than in academic libraries (31.5\%). This finding would suggest a shift in employer attitudes and a worrying (if accurate) lack of concern in the academic sector that professional standards be maintained. Again, further research is required to illuminate this area. A notable proportion $(34.5 \%)$ of those successfully completing had received some form of financial reward for their achievement.

The majority of respondents were interested in their personal continuing professional development (93.5\%). $85.4 \%$ felt that CPD was important for their careers. The largest proportion of respondents read professional literature as part of their CPD (85\%), while between a half and two thirds attended external seminars/courses, networked with colleagues and engaged in internal training activities. Just over a third were involved in professional activities and took part in electronic discussion lists (more commonly in the academic sector). Only small numbers were engaged in seeking further academic qualifications or 
professional/vocational qualifications. The fact that disappointingly few respondents were engaged in any formal educational process suggests that the concept of lifelong learning has not been seized upon as enthusiastically as might have been hoped.

A slight majority of respondents (54.2\%) felt that CPD should not be compulsory, citing as reasons: their belief in freedom of choice; lack of motivation; conflicting pressures; and fear of penalties. Some suggested a system of reward rather than a compulsory approach should be preferred. Those that believed that CPD should be compulsory (41.2\%) justified their belief on the basis that CPD is essential in maintaining currency of skills and made the point that CPD is compulsory in other highly regarded professions, such as law and medicine. It is felt that this is an area which requires further exploration: in examining in detail compulsory approaches taken in other professions; and in debate between the professional association, members at a variety of stages in their careers and employers.

Respondents felt that their employer saw CPD as being necessary all of the time (38.2\%) or sometimes $(34.3 \%)$ and only $10.8 \%$ felt that their employer thought CPD was unnecessary. Most respondents thought that CPD should be the responsibility of both the employer and the employee (53.9\%), while $39.2 \%$ felt that responsibility should lie solely with the employee. This result would reinforce uncertainty about the positive value of developing some compulsory mechanism in ensuring that CPD takes place for Associates of the Library Association. These data are in line with the findings of earlier research (Farmer and Campbell, 1997) that LIS professionals are apathetic about and suspicious of getting involved in CPD activities.

Despite a high level of awareness of the LA CPD Framework, a substantial proportion of respondents found it inappropriate to their needs. As in Redfern (1996) and Nankivell (1997b), respondents were not making use of the LA CPD Framework: the present study would suggest that it is the relevance of the Framework to individual professionals' working environment and their career patterns that should be examined. Further exploration is needed to identify ways in which the Framework might be tailored to fit better with professionals' requirements. 


\section{Recommendations}

The Library Association must steer a delicate course between making the process of attaining Associateship a feasible and responsive one for candidates and ensuring that it remains sufficiently challenging to guarantee high standards in the profession.

A similar dilemma faces the LA in deciding upon the appropriate course of action to follow in developing their CPD programme: a compulsory approach would appear not to be particularly popular amongst respondents in the present study and yet it would be a useful mechanism in ensuring that high professional standards are applied to Associates throughout their professional careers. Further exploration of and debate on compulsory approaches to CPD should take place. The LA CPD Framework should also be revised with particular attention to its relevance to a wide variety of career patterns.

Further research into attitudes amongst employers to Associateship is urgently required in order both to develop better mechanisms for encouraging candidates' completions of the process but also to test whether respondents' perception of diminishing employer support are based in fact. Debate must take place with employers in order to develop a model of best practice in support of candidates and to explore ways in which motivation towards successful completion may be built into employment practice. A programme to promote the advantages of Associateship should be put in place aimed both at prospective candidates and employers (particularly in the academic library sector).

There are a number of ways in which candidates' support might be improved. The mentors network should be extended to be made available to Route A candidates. Guidelines should be revised to include advice on techniques to assist candidates in overcoming predictable barriers to successful completion. Training sessions should be designed to include more scope for consideration of the individual circumstances of those attending.

No limit on the time available for completion of the process of attaining Associateship should be introduced: however, candidates exceeding a three year period of registration should be required to submit a progress report and an outline schedule for completion. A process for the reporting of poor supervision should be put in place. 


\section{References}

[1] M. Freeman. A sense of direction: librarianship and CPD. Librarian Career Development 2(3) (1994) 26-28.

[2] M. Redfern. The condition is critical: continuing professional development of library and information services staff. Health Libraries Review 12(1) (1995) 13-21.

[3] S. Pantry. Be a successful library and information professional. Learning Resources Journal 12(3) 1996, 61-64.

[4] J. Parry. Maintaining quality through continuing professional development. Impact, the Journal of the Career Development Group 1(3) (1998) 34-37.

[5] J. Elkin. Personal development: looking at further opportunities. Assistant Librarian, 90(9) (1997) 139-144.

[6] E. Doney. Developing opinions: the attitudes of ILS staff to continuing professional development. Library Management 19(7), 1998, 486-491.

[7] E. Hyams. Professional associations and the role of CPD. Assignation 15(3) (1998) 8-11.

[8] J. Elkin. The role of LIS schools and departments in continuing professional development. Librarian Career Development 2(4) (1994) 19-23.

[9] A. Abell. New roles? New skills? New people? Library Association Record 99(10) (1997) 538-539.

[10] J. Farmer and F. Campbell. Continuing Professional Development and career success: is there a causal relationship? London: British Library Research and Innovation Centre, 1998. [British Library Research and Innovation Report no. 112]

[11] J. Farmer and F. Campbell. Reaching beyond the plateau: identifying special librarians' transferable skills through "learning pairs". London: British Library Research and Innovation Centre, 1997. [British Library Research and Innovation Report no. 46]

[12] B. Fisher. Do as I do. Library Association Record 99(10) (1997) 544-545.

[13] C. Nankivell. Essentials of a good relationship. Library Association Record 99(10) (1997) 545 .

[14] P. Levy. An example of Internet-based continuing professional development: perspectives on course design and information. Education for Information 17(1) (1999) 45-58.

[15] C. Horseman. CD-Rom: tailor-made for training? Library Association Record 99(10) (1997) 550-552.

[16] L. Swaffield. How the others stay on top. Library Association Record 99(10) (1997) 536-537. 
[17] Library Association. The Framework for Continuing Professional Development: your personal profile. London: LA, 1992.

[18] M. Redfern. I wannabe: the Framework for Continuing Professional Development. Librarian Career Development 1(1) (1993) 5-8

[19] D. Birkinshaw. The Framework for Continuing Professional Development: an employee's perspective. Personnel Training and Education 10(1) (1993) 6.

[20] C. Smith. The Framework for Continuing Professional Development: implications for employers. Personnel Training and Education 10(1) (1993) 5.

[21] M. Redfern. Is CPD a growing force? Library Association Record 98(5) (1996) 254255.

[22] C. Nankivell. Have you been framed? Library Association Record 99(10) (1997) 553554.

[23] K. Wood. More flexible routes to LA qualifications. Library Association Record 97(1) (1995) 30-31,33.

[24] M. Huckle. Becoming a professional. Library Association Record 100(5) (1998) 254.

[25] C. Atton. The professional development report: a writer's guide. Assistant Librarian 87(6) (1994) 94-95.

[26] J. Kempshall and A. Casey. Spare a thought for the supervisors. Assistant Librarian 85(12) (1992) 184-185.

[27] S. Burton and M. Huckle. Try mentoring: candidates on Route B to Associateship need your support. Impact, the Journal of the Career Development Group 2(2) (1999) 2122.

[28] A. Turriff. If you are chartered... read. Scottish Libraries 13(2) (1999) 16-17.

[29] Medical Library Association. The Academy of Health Information Professionals. Available online at http://www.mlahq.org/academy/. Viewed 18 February 2000.

[30] Library and Information Association of New Zealand Aotearoa. Procedures handbook for the award of Associateships, Fellowships and Letters of Recognition. Available online at http://www.lianza.org.nz/code_3.htm. Viewed 18 February 2000.

[31] American Library Association. Office for Human Resource Development and Recruitment. Available online at http://www.ala.org/hrdr/. Viewed 28 February 2000.

[32] Special Libraries Association. A visionary framework for the future: SLA's strategic plan. Available online at http://www.sla.org/assoc/slaplan.html. Viewed 28 February 2000.

[33] Canadian Library Association. About CLA. Available online at http://www.cla.ca/about/About.htm. Viewed 18 February 2000. 
[34] Australian Library and Information Association. Continuing professional development. Available online at http://www.alia.org.au/gc/committees/boe/cpd.html. Viewed 18 February 2000 .

[35] International Federation of Library Associations and Institutions. Round Table on Continuing Professional Education. Available online at http://www.ifla.org/VII/rt7/rtcpe.htm. Viewed 16 February 2000.

[36] P.L. Ward and D.E. Weingand, D.E., eds. Human development: competencies for the twenty-first century. Papers from the IFLA CPERT Third International Conference on Continuing Professional Education for the Library and Information Professions. Munich: K.G. Saur, 1997.

[37] J. MacDougall, H. Lewins and G. Tseng. Continuing education and training opportunities in librarianship. London: British Library, 1990. (British Library Research Paper no. 74)

[38] T. Whitehall, L.G. Durbridge and A.J. Meadows. Communication between library practitioners. Library Review 38(1) (1989) 7-33.

[39] N. Roberts and T. Konn. Librarians and professional status: continuing professional development and academic libraries. London: Library Association, 1991.

[40] Scottish Library and Information Council. Continuing professional development for library and information staff. Glasgow: SLIC, 1993 